\title{
A Strategy of Learning Computational Thinking through Game Based in Virtual Reality: Systematic Review and Conceptual Framework
}

\author{
Sukirman SUKIRMAN ${ }^{1,2}$, Laili Farhana Md IBHARIM ${ }^{1 *}$, \\ Che Soh SAID ${ }^{1}$, Budi MURTIYASA ${ }^{2}$ \\ ${ }^{1}$ Faculty of Art, Computing, and Creative Industry, Universiti Pendidikan Sultan Idris, \\ Perak, Malaysia \\ ${ }^{2}$ Faculty of Teacher Training and Education, Universitas Muhammadiyah Surakarta, Indonesia \\ e-mail:sukirman@ums.ac.id, laili@fskik.upsi.edu.my, chesoh@fskik.upsi.edu.my,Budi.Murtiya- \\ sa@ums.ac.id
}

Received: February 2021

\begin{abstract}
Research trends on computational thinking (CT) and its learning strategies are showing an increase. The strategies are varying, for example is using games to provide enjoyment, engagement, and experience. To improve the high level of immersion and presence of game objects, learning strategies through games can be improved by virtual reality (VR) technology and its application. However, a systematic review that specifically discusses game based in VR (GBiVR) settings is lacking. This paper reports previous studies systematically about the strategies used to learn CT through games and VR applications. 15 papers were selected through Preferred Reporting Items for Systematic Reviews and Meta-Analyses (PRISMA) guidelines. As the result, this study proposes a conceptual framework for designing a strategy to learn CT through GBiVR settings. The framework consists of critical aspects of variables that can be considered in the learning environment like game elements, VR features, and CT skills. All the aspects are discussed below.
\end{abstract}

Keywords: systematic review, conceptual framework, computational thinking, game-based learning, virtual reality, prisma.

\section{Introduction}

Research trends on computational thinking (CT) are showing an increase in recent decades (Ilic et al., 2018; Tang et al., 2020). It can be seen from the international research publications about CT or relates are improved in two periods (2006-2012

\footnotetext{
* Corresponding author
} 
and 2013-2018) from 3798 to 7175 or escalated narrowly double, whereas it is only indexed by Web of Science (WoS) (Tang et al., 2020). The researches also showed that subjects and participants involved are not only higher education degrees, but also secondary level and even primary students, for example, Fagerlund et al. (2020) even conducted a research to assess CT skills of 4th grade students through Scratch programming projects. One of the reasons why this research is growing because CT offers a set of strategies to resolve complex problems by applying computer sciences' reasoning processes (Hooshyar et al., 2021). In the computer science (CS) area itself, Zhang \& Nouri (2019) stated that CT is considered as the core amongst prevalent topics such as computing, programming, coding, and problem-solving as illustrated in Fig. 1. They added that programming and coding are often interchangeable in colloquial use. Coding can be pointed as the writing of computer programming code, while programming itself is more than just coding since involves complex tasks such as understanding a problem, designing, coding, and maintenance. The larger concept is computing which covers CT, coding, programming, and computing. Hence, students who mastered CT are potentially to resolve problems encountered in programming scope or related it as well. As we know, programming lies behind all digital technology, software, and systems around us today. However, CT is not merely about CS, but it is a combination of thinking skills that are crucial for handling complex problems, such as theoretical (mathematical) thinking, engineering thinking, and scientific thinking (Chou, 2019).

CT is described as thought processes involved in formulating problems and their solutions that are represented in an effective form to be carried out by an informationprocessing agent (Cuny et al., 2010). CT is believed as one competence that should be expertized by all educational levels of 21 st-century students as it promotes a way of thinking inspired by CS styles in solving problems (Nouri et al., 2020; Zhang \& Nouri, 2019). Even, Wing (2006) argued that CT is not only for CS students, but it is a fundamental skill that should be understood by everyone outside CS learners, like reading, writing, and arithmetic. By learning CT, students may benefit from the principles, concepts, and approaches commonly applied to computer science.

Many countries have started or currently in the process to introduce CT and CS or elements thereof in their official national curricula, for example, England, Finland, Sweden, Portugal, Malaysia, and many others (Nouri et al., 2020; Saad, 2020). They

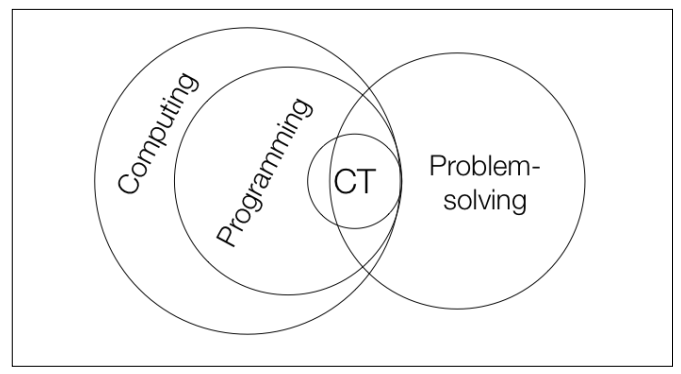

Fig. 1. Relationship among prevalent topics. 
realize that CT is important for everybody since we live in this digital era and deal with technology based on computers. In Indonesia, the ministry of education and culture (Kemdikbud) issued a regulation to apply CS in the middle (junior and high) schools as a standalone subject with the name "Informatika", where the basic core of the subject is CT (Kemdikbud, 2019). In this subject, CT is placed in the bottom layer among the foundation of knowledge area, computing practice, and information communication technology (ICT). However, CT actually has been introduced in many countries through the Bebras challenge, an international competition that aims to promote $\mathrm{CT}$ among students of all levels since several years ago (Bavera et al., 2020). More than 50 countries are currently participating in this challenge which is the involved participants do not require to have prior knowledge of programming or CS. It means that CT has internationally acknowledged and should be adopted to prepare a better young generation. As it is known, today's society is massively computerized in all spheres.

Along with the advance of CS and its applications today, many studies reported that integrate CT into school curricula would benefit students learning processes, both cognitive and non-cognitive aspects (Hooshyar et al., 2021; Malva et al., 2020; RománGonzález et al., 2017). Lot of tools and devices used for teaching CT are becoming more diverse, from visual block-based programming like Scratch, Blockly, Kodu, Construct 2, and App Invertor (Zhang \& Nouri, 2019), as far as augmented reality (AR) (Cleto et al., 2020) and virtual reality (VR) application (Chen et al., 2020). Additionally, strategies adopted for learning CT are also varying, for example, project-based learning, problembased learning, cooperative learning, and game-based learning (GBL) (Hsu et al., 2018). The majority goal is to improve the learning processes to be fun for all students, provide enjoyment, engagement, and getting more experiences.

One popular setting employed to teach CT that allows learners more enjoy and free to demonstrate their own goals is GBL (Hsu et al., 2018). This strategy offers a high degree of autonomy and lets learners make multiple decisions on how to execute and how the approach that used to tackle the problems which encountered in the environment (Nietfeld, 2020). Actually, the approaches to acquire CT with GBL can be designed in two settings, (1) learning through designing a game and (2) learning through gameplay (Turchi et al., 2019). Learning through designing a game entails students to design and develop a game that contains goals and rules so that can be played by others. The activities and instructions are followed by students and they learn from the challenging tasks assigned. When learning to design and develop a game, learners may study CT such as problem-solving, decomposition, abstraction, and pattern recognition (Cetin, 2016; Turchi et al., 2019). Meanwhile, learning through gameplay refers to learners acquire CT concepts by playing a game and accomplish the tasks provided in the games. For example, Penguin Go, a video game designed with Blockly to facilitate students of middle schools for learning CT (Zhao \& Shute, 2019). In this game, students may learn an algorithm concept by developing a sequence of steps and explicitly put them into a program.

To enhance users' experience in a high level of immersion and presence, the learning strategy through gameplay settings in a game can be designed through VR features (Radianti et al., 2020). It is because VR provides a sense of "being" in the task environment instead so that makes users feel actually "there". VR is an artificial object and 
its environment generated by computer technologies to simulate real-world artifacts and provide a new digital environment that makes users feel like present in the new world (Berntsen et al., 2016). Applying a game based in virtual reality (GBiVR) for training or learning means incorporating learning material contents into the gameplay to enhance playability, interactivity, playfulness, presence, and immersion so that makes users more enjoy while studying. Compared to just a VR learning environment (VRLE) only, GBiVR offers more challenges and enjoyment that encourage learning motivation (Giannakos, 2013). Additionally, compared to traditional classroom instruction, Shi et al. (2019) stated that GBiVR has two promising characteristics, they are 1) active learning driven by the experience of challenge, engagement, and playfulness; and 2) representation of situated knowledge which provides facilities knowledge acquisition.

Due to the increasing scholarly attention to CT learning, there have been several systematic reviews of tools or strategies employed to teach or learn CT, such as visual block-based programming Scratch (Zhang \& Nouri, 2019), robot (Yang et al., 2020), toys and kit (Yu \& Roque, 2019) or even without a computer and its application named as "unplugged" (Huang \& Looi, 2020). However, a systematic review that specifically discusses GBiVR as a tool and strategy for learning CT is lacking or even has not been conducted. Therefore, this paper aims to investigate systematically from previous studies about the strategy that can be used for learning CT through GBiVR. The main research question (RQ) of this study is "What are the essential factors that should be considered in developing a strategy to learn CT through GBiVR?". Based on the review, we propose a conceptual framework of learning CT through GBiVR that potentially can be used to guide the development and implementation of the strategy to learn CT through GBiVR.

\section{Methodology}

This systematic review employs Preferred Reporting Items for Systematic Reviews and Meta-Analyses (PRISMA) guidelines that consist of four steps, namely identification, screening, eligibility, and included as illustrated in Fig. 2 (Liberati et al., 2009). This strategy was chosen due to the direction allows us to reduce potential bias, produce a good quality of the reports and meta-analysis, and may be adopted to all types of systematic reviews, not limited to clinical trials (Salvador-Ullauri et al., 2020). Additionally, PRISMA provides checklist items that lead us to analyze and synthesize the data collected systematically.

\subsection{Search Strategies and Database Sources}

Determining appropriate keywords and selecting databases are the most crucial steps in a systematic review. The results may affect to the answer of research questions. The keywords used in this systematic review are "computational thinking", "game" 


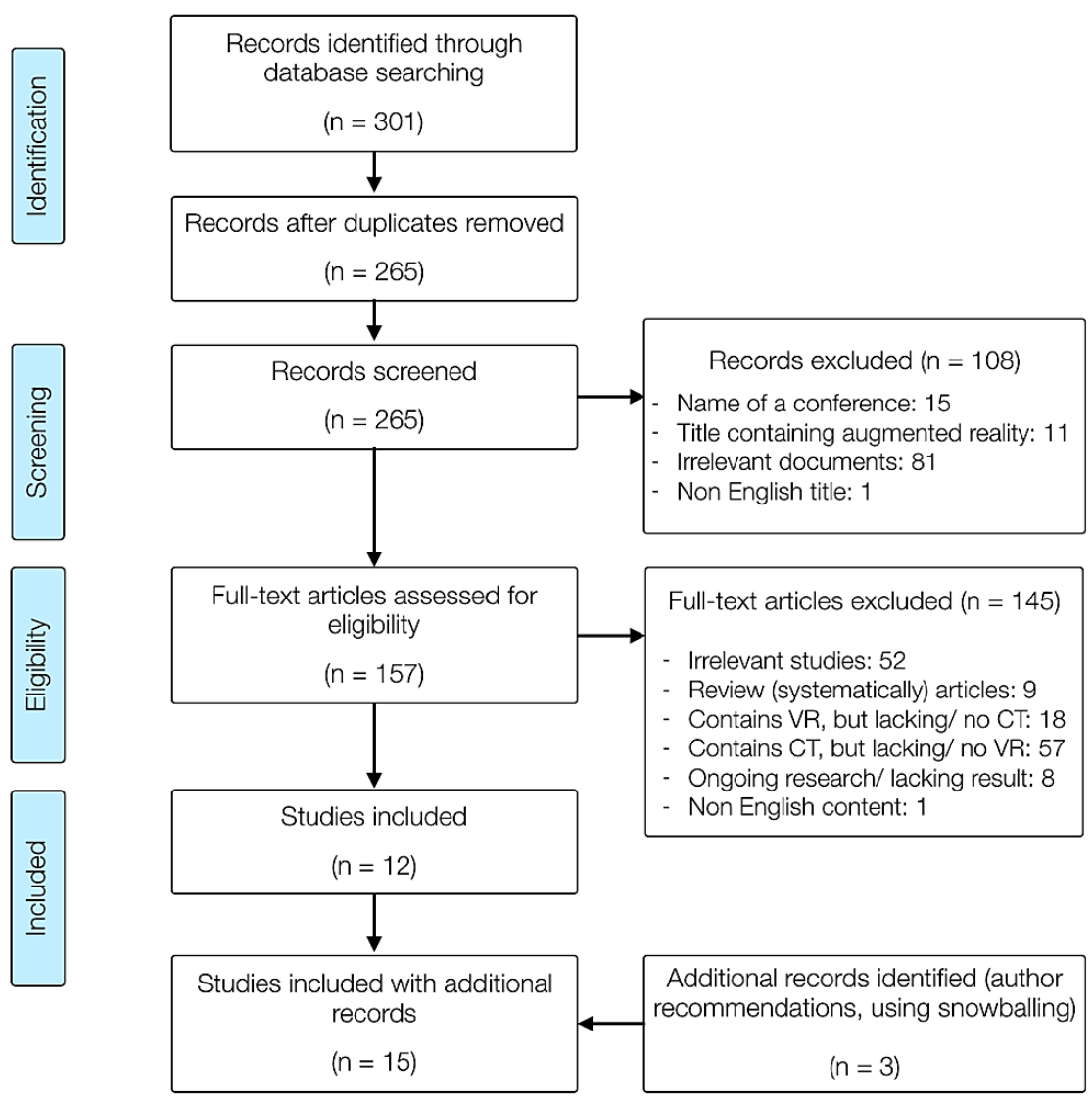

Fig. 2. PRISMA flowchart employed in this study.

and "virtual reality". The searching strategies were performed by the combination of keywords separately and sequentially utilizing the feature of "search within results", namely "computational thinking" followed by "game" and then "virtual reality". The searching was performed to the database sources that provide a facility of "search within results", namely Scopus, Web of Science (WoS), and IEEE Xplore. Additionally, the searching was also conducted to ACM digital library, Science Direct, Springer Link, and Wiley Online Library in a slightly different way due to the facility of "search within results" is not provided. However, the keywords and combinations used were kept in the same, utilizing the Boolean operator "AND" and quotation mark. The final search was carried out in the last week of November 2020 which yielded 301 documents. The detailed result obtained by the search protocol that has been defined previously is provided in Table 1. It can be seen that the most found documents are recorded in the Scopus database followed by Springer Link, they are 109 and 98 respectively. However, the records still need to be assessed to find out the requirements of inclusion criteria. 
Table 1

Detail results obtained by the search protocol

\begin{tabular}{lc}
\hline Database sources & Documents identified \\
\hline Scopus & 109 \\
WoS & 6 \\
IEEE Xplore & 13 \\
ACM Digital Library & 48 \\
Science Direct & 16 \\
Springer Link & 98 \\
Wiley Online Library & 11 \\
Total & 301 \\
\hline
\end{tabular}

\subsection{Eligibility Criteria}

Before screening processes, the duplicate records generated by the different databases should be removed first, and they remained 265 documents. The records excluded from the screening processes were 108 and remained 157 documents. The record was eliminated when it met the exclusion criteria, and it will be selected when it met the inclusion criteria as seen in Table 2. The conference name was excluded because it is just the name of event and there was no content related to the RQ. Irrelevant documents refer to the records that do not contain both CT and VR, so that although the record contain CT but does not contain VR or the opposite, it was excluded. The documents also must be written in English, if not in English, they will be excluded. The record was also excluded if it was a research that has not been accomplished or ongoing research, so that it was lacking result that cannot be analyzed further. The documents that contain the word "augmented reality" were also excluded due to its characteristic is different from VR, start from the definition until the device used. Based on the criteria provided in Table 2, we excluded 145 documents as ineligible criteria and remained 12 records as eligible criteria.

After finished all the steps within PRISMA guidelines, we included 3 additional papers that are considered eligible but escaped from the search processes that recommended by the other authors. It was carried out by a snowballing approach, a strategy to retrieve relevant articles based on target papers' references list or paper citing (Wohlin, 2014). The criteria of inclusion and exclusion were also same as the ones applied in

Table 2

Exclusion and inclusion criteria

\begin{tabular}{ll}
\hline Exclusion criteria & Inclusion criteria \\
\hline Name of conference events & Non-review articles \\
Irrelevant documents & Relevant studies \\
Non English documents & Written in English \\
Ongoing research publications & Completed research \\
Contain word "augmented reality" & Appropriate to the research question
\end{tabular}


the PRISMA framework. Initially, some authors recommended 5 additional articles to be included, but after scrutinized and analyzed the contents, we decided excluded 2 articles. We excluded them because the articles were not containing CT contents despite them containing VR and learning outcomes. The aforementioned processes through PRISMA guidelines are diagrammatically illustrated in Fig. 2. The final result of the papers that we identified as being relevant to this systematic review is 15 documents. The selected documents have been through rigorous screening based on determined criteria written in Table 2.

\subsection{Quality Assessment of the Documents}

The next step is assessing the quality of selected papers. To assess the quality, we adopted an assessment strategy proposed by Feng et al. (2018) and Connolly et al. (2012). The assessment of the selected documents of this study was involving in two raters using the questions below:

i. How relevant is the focus of the study to address the research question of this review?

ii. How appropriate are the methods and analysis used to answer the research question of this review?

iii. How appropriate is the research design for addressing the research question?

A score of the weight of evidence (WoE) that is used to assess the quality of papers is between 1 and 3, which means 1 is low quality, 2 is medium, and 3 is a high-

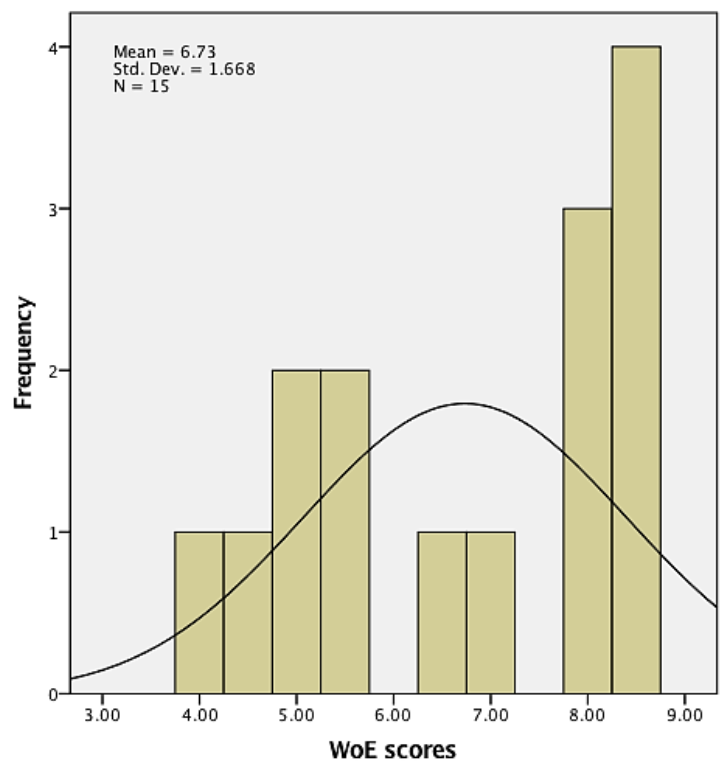

Fig. 3. Weight of Evidence (WoE) scores calculated from 15 selected papers. 
quality article. Based on the 3 provided questions above, an article has a score between 3 and 9. Each paper is assessed by two raters from an internal author and an external author who has the same background research in VR or CT. The scores were then calculated to obtain the mean of the final score to represent the quality of all reviewed articles in this study. The mean score of 15 papers is 6.73 , while the standard deviation is 1.668. Fig. 3 illustrates the histogram that describes the frequency score of 15 papers assessed by two raters. It can be seen that the curve illustrated in the histogram is leftskewed which the mean score is closer to the left. Therefore, it shows that the quality of selected articles quite good.

\subsection{Data Extraction and Analysis}

Final selected papers were extracted by reading each full-text manuscript and coding it with a scheme in an Excel file format. Therefore, the findings were systematically well organized to ease the analysis. The coding scheme was compiled based on the formulated research questions and the available detailed information in the papers. The main scheme was arranged through the following fragments:

- Author information consists of the authors' last name and publication year.

- The title of the reviewed manuscript.

- Objectives of the study.

- Methodology, research design, or strategies adopted in the research.

- Obtained results and conclusions based on the findings and discussions.

- Elements or factors considered in the research.

- Research variables including independent and dependent variables.

- Strategies and instruments to collect data.

- Challenges, limitations, and future works.

\section{Results}

This section provides the findings based on 15 papers that have been selected, coded, and analyzed systematically. It consists of 10 conference proceedings papers, and 5 others are articles published in journals as provided in Table 3. The articles were published by reputable publishers such as the Institute of Electrical and Electronics Engineers (IEEE), Association for Computing Machinery (ACM), Springer International Publishing, Routledge - Taylor \& Francis, and John Wiley \& Sons, Ltd. They are known as a good quality publisher in many spheres, mainly computer science and related. The majority of the articles are published in 2020, namely 7 articles, followed by 2019 which consists of 5 articles, and 3 others are published in 2018, 2017, and 2016. It means that the articles are fresh and up to date since the publications are recently issued. The number of publications is also showing an increase, which means that the trend about the strategy of learning CT and its related through game based in VR settings is positively growing over the year. 
Table 3

Selected papers based on inclusion criteria

\begin{tabular}{clll}
\hline No. & Authors \& Year & Types & Publisher \\
\hline 1 & (Parmar et al., 2016) & CP & IEEE \\
2 & (Lin et al., 2017) & CP & ACM \\
3 & (A Dengel, 2018) & CP & IEEE \\
4 & (Banic \& Gamboa, 2019) & CP & IEEE \\
5 & (Berns et al., 2019) & CP & ACM \\
6 & (Kao, 2019) & CP & ACM \\
7 & (Lai et al., 2019) & JA & Routledge \\
8 & (Turchi et al., 2019) & JA & Springer \\
9 & (Andreas Dengel, 2020) & CP & ACM \\
10 & (Chen et al., 2020) & JA & Frontiers \\
11 & (Jin et al., 2020) & CP & ACM \\
12 & (Leonard et al., 2020) & JA & Routledge \\
13 & (Nguyen et al., 2020) & CP & Springer \\
14 & (Pearl et al., 2020) & CP & ACM \\
15 & (Segura et al., 2020) & JA & John Wiley \& Sons, Ltd \\
\hline
\end{tabular}

$\mathrm{CP}$ : conference proceeding

JA: journal article

\subsection{Learning Objectives and Pedagogical Types}

Based on the 15 selected papers for review, it was identified that the main objectives of the studies can be classified to be four categories, namely fostering CT, introducing programming concepts, teaching CS concepts, and leveraging CT concepts in courses for problem-solving. All of the studies were set up in the VR environment either in game-based learning (GBL) settings or non-GBL settings. Fig. 4 illustrates the total number of each setting based on the objective categories classified in Fig.1. It can be

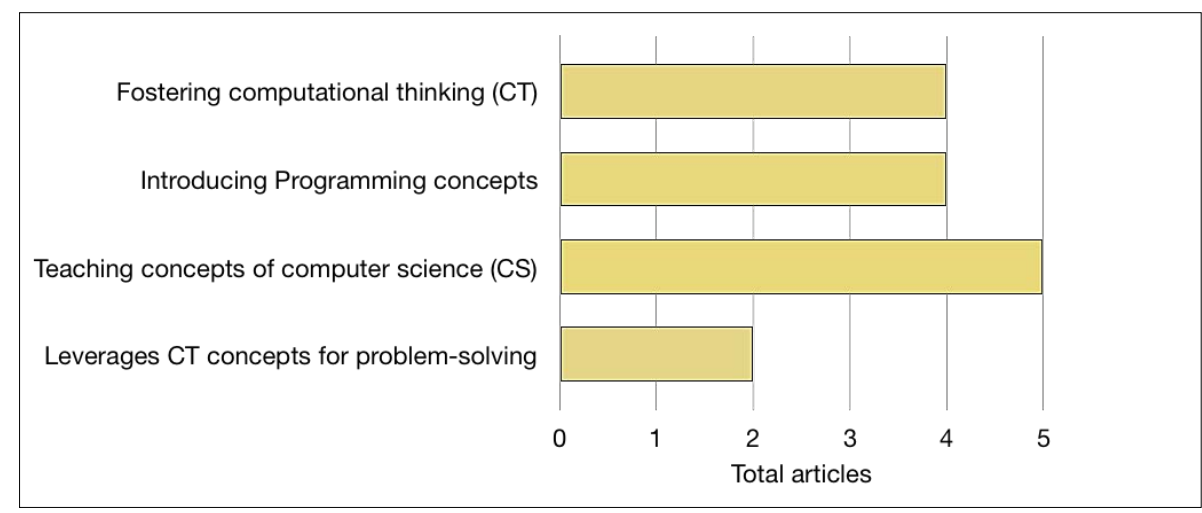

Fig. 4. Main objectives of the studies. 
seen that teaching the concepts of CS is the most widely conducted which a total of 5 articles, while leveraging CT concepts for problem-solving is the lowest one which only 2 papers.

More deeply related to $\mathrm{CT}$, it can be grouped to become two pedagogical types, namely (1) CT acts as a learning outcome, and (2) CT acts as a strategy of learning. Table 4 shows the objectives classification based on the pedagogical types. CT acts as a strategy of learning means utilizing or incorporating CT concepts for an approach to tackle the problem as the research conducted by Lai et al. (2019) and Chen et al. (2020). Lai et al. (2019) integrate the concept of CT education into a course on plot image-based VR. In that research, students were allowed to demonstrate the CT skills to resolve problems that designed in the plot such as broke the plot down into problem decomposition, problem exploration, and program algorithm. Meanwhile, Chen et al. (2020) combine head-mounted VR and CT experiments to drive students to create ideas for real disaster relief scenarios. In their research, students were allowed to think about different script situations to find a suitable maker design for the project.

$\mathrm{CT}$ acts as a learning outcome means that CT is set up for the goal of learning. The example is the research that conducted by Turchi et al. (2019), Jin et al. (2020), Leonard et al. (2020), and Pearl et al. (2020). Turchi et al. (2019) conducted a research to improve CT skills emphasizing two different elements provided in GBL settings, namely playfulness, and collaboration. They investigate whether the CT skills can be enhanced through gameplay in a GBL setting or vice versa. The result stated that the overall response was showing positive feedback despite the participants needed some practices at the beginning. Slightly different from Turchi et al. (2019), Leonard et al. (2020) taught CT through the creating of dance performances for virtual characters in a VR environ-

Table 4

Classification of objectives based on pedagogical types

\begin{tabular}{|c|c|c|c|}
\hline Objectives & Including & $\begin{array}{l}\text { Pedagogical } \\
\text { types }\end{array}$ & Authors \\
\hline $\begin{array}{l}\text { Leverages CT } \\
\text { concepts for } \\
\text { problem-solving }\end{array}$ & $\begin{array}{l}\text { Integrating CT concepts into plot planning, } \\
\text { leveraging CT concepts to create ideas for } \\
\text { disaster scenarios }\end{array}$ & Strategy & $\begin{array}{l}\text { (Lai et al., 2019), (Chen et al., } \\
\text { 2020) }\end{array}$ \\
\hline $\begin{array}{l}\text { Teaching CS } \\
\text { concepts }\end{array}$ & $\begin{array}{l}\text { Facilitates learning CS, enhance the under- } \\
\text { standing of CS, teaching CS itself, making } \\
\text { CS more tangible, presenting CS concepts }\end{array}$ & Outcome & $\begin{array}{l}\text { (Parmar et al., 2016), (A Den- } \\
\text { gel, 2018), (Banic \& Gamboa, } \\
\text { 2019), (Berns et al., 2019), } \\
\text { (Andreas Dengel, 2020) }\end{array}$ \\
\hline $\begin{array}{l}\text { Introducing } \\
\text { Programming } \\
\text { concepts }\end{array}$ & $\begin{array}{l}\text { Introduce programming concepts, Aid users } \\
\text { learning (Java) programming, propose } \\
\text { a programming environment based on VR, } \\
\text { teaching the basic programming concepts }\end{array}$ & Outcome & $\begin{array}{l}\text { (Lin et al., 2017), (Kao, 2019), } \\
\text { (Nguyen et al., 2020), (Segura } \\
\text { et al., 2020) }\end{array}$ \\
\hline Fostering CT & $\begin{array}{l}\text { Fostering CT through collaborative game- } \\
\text { based learning, to boost children's creativity } \\
\text { and CT skill, teaching CT, to lower the thre- } \\
\text { shold the construction of computational } \\
\text { algorithms }\end{array}$ & Outcome & $\begin{array}{l}\text { (Turchi et al., 2019), (Jin et al., } \\
\text { 2020), (Leonard et al., 2020), } \\
\text { (Pearl et al., 2020) }\end{array}$ \\
\hline
\end{tabular}


ment. Students were explained that dance choreography and computer programming have similar compositional processes. Therefore, the students were set to engage in several choreographic and programming tasks. From this setting, the students can learn several computational concepts like repetition as loop, theme-and-variations as Boolean logic, variations as variables, and unison in dance as parallelism. The research showed that students' CT abilities were improved.

However, the majority of the studies sought to make the learning of CT and prevalent topics to be more fun and more provided new experiences through VR technology. With the new settings in the VR environment, students can learn more engage and enjoy the activities. Students also can improve their knowledge, abilities, and change their perceptions about who computer scientists are and what they actually do (Leonard et al., 2020). Additionally, students are also motivated and unleash their ability to think more creatively and differently to solve a problem (Chen et al., 2020).

\subsection{Study Designs and Settings}

From the 15 selected papers, experimental research is the type most employed as illustrated in Fig. 5, namely 33\% or 5 articles (Banic \& Gamboa, 2019; Chen et al., 2020; Lai et al., 2019; Lin et al., 2017; Segura et al., 2020), followed by exploratory $27 \%$ or 4 articles (Andreas Dengel, 2020; Leonard et al., 2020; Parmar et al., 2016; Turchi et al., 2019), and pilot testing 20\% or 3 articles (Berns et al., 2019; Jin et al., 2020; Nguyen et al., 2020). Meanwhile, 13\% or 2 articles (A Dengel, 2018; Pearl et al., 2020) are unclearly explained and $7 \%$ or 1 article (Kao, 2019) employed research and development (R\&D) by recruiting experts through an online portal. In the experimental research, Segura et al. (2020) conducted three times experiment with different purposes of each, namely (1) to evaluate the general performance of the system and its user experience, (2) to assess the acceptance of users, and (3) to evaluate whether the designed system is better or the opposite which was set up through the experimental group and control group.

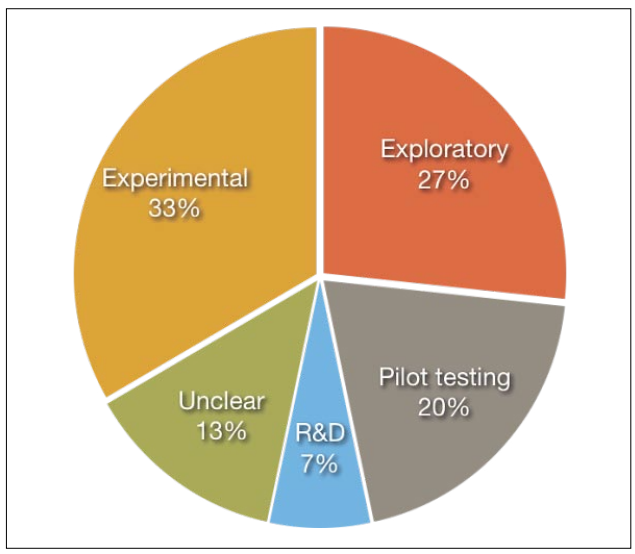

Fig. 5. Study designs that employed in the researches. 
Almost all research in the experimental type is designing the setting in two groups, intervention or experimental group and control group. The difference is the approach used, for example, Banic \& Gamboa (2019) employed visual design problem-based learning by allowing students to create 3D sculptures compared to traditional strategy, while Lin et al. (2017) allowed both groups to use the developed system with different tasks. Lai et al. (2019) and Chen et al. (2020) almost had the same design, grouping the classes into two groups with the same treatment at the beginning to make sure that all groups had the same basic knowledge, then made different interventions in the middle of learning processes to identify the differences between the intervention group and natural group.

In the exploratory type, Parmar et al. (2016) and Leonard et al. (2020) almost used the same design. They allowed students to create dance choreography with a CT concepts approach. The differences are Leonard et al. (2020) needed a longer time and more participants involved than Parmar et al. (2016). Meanwhile, both Turchi et al. (2019) and Andreas Dengel (2020) divided the participants into several groups, eight and three respectively. The participants were allowed to play the game designed by both researchers, then they explored and observed the participants' attitude toward overall the application system. Additionally, they also asked participants to complete questionnaires provided by the researchers.

\subsection{Variables and Learning Impacts}

Table 5 shows the classification of variables that are generally concerned in the research based on the 15 reviewed papers. We categorized them into four types such as game

Table 5

Classification of the research variables

\begin{tabular}{llll}
\hline Game Elements & CR Features & CT Concepts & Learning impacts \\
\hline Playability & Telepresence & Decomposition & Creativity \\
Engagement & Social presence & Pattern recognition & Self-directed learning/ autonomy \\
Excitement & Metaphorical representation & Abstraction & Independently \\
Interesting & Presence & Algorithm design/thinking & Persistence/Maintain \\
Enjoyment & Immersion & Answer set programming & Learning experience \\
Customization & Embodied interaction & Finite state machine & Learning interest \\
Playfulness & Social interaction & Problem-solving & Learning motivation \\
Collaborative & Visibility of abstract & Recursively thinking & Learning outcomes \\
Interactivity & Visual aspects & Heuristic & Knowledge, \& comprehension \\
Visual layout & & Data representation & Practical motivation \\
& & Debugging (evaluating & The mental model of computer \\
& & solutions) & scientists \\
& & Sequence & Common sense \\
& & Loop & Creative thinking \\
& & Variable & Systemic reasoning \\
\hline
\end{tabular}


elements, VR features, CT concepts, and learning impacts. The elements of the game consist of playability, engagement, excitement, interesting, enjoyment, customization, playfulness, collaborative, interactivity, and visual layout. Meanwhile, elements of VR are telepresence, social presence, metaphorical representation, presence, immersion, embodied interaction, social interaction, and visibility of the abstract objects. CT elements consist of decomposition, pattern recognition, abstraction, algorithm design/ thinking, answer set programming, finite state machine, problem-solving, recursively thinking, heuristic, data representation, debugging (evaluating solutions), sequence, loop, and variable. In the meanwhile, learning impacts comprise creativity, self-directed learning/ autonomy, independently, persistence/maintain, learning experience, learning interest, learning motivation, learning outcomes, knowledge \& comprehension, practical motivation, mental model of computer scientists, common sense, creative thinking, and systemic reasoning. Based on these variables and the categories, we constructed a conceptual framework that is discussed in the next separated section.

The first variable in the game elements is playability, which refers to how easy or how long duration of a game can be played by users. Playability is closely related to others variables in the game elements. According to Paavilainen (2020), the playability of a game is defined as the design quality of the game, formed by its functionality, usability, and gameplay. However, he argued that games with good playability are not necessarily fun, sometimes games with poor playability may provide an enjoyable experience. The main objective of playability is to provide enjoyment and playfulness. Hence, it can improve the excitement and interest to play the games. As the research conducted by Parmar et al. (2016) and Banic \& Gamboa (2019), they are more concerned about the enhancement of users' engagement prefer than playability. Their strategies were to design enjoyable tasks with an interesting visual layout and provide a virtual character with the immersive embodied interaction supported by VR technology. Hence, utilizing game elements in the VR settings can improve user experiences and playability as well.

In the VR environment, Parmar et al. (2016) measured telepresence by designing various questions that lead to the sense of "being there", for example, "Did you feel like you were inside and surrounded by the environment?". If we analyzed, it is similar to the term "presence" or "virtual presence" as stated by Lombard \& Ditton (1997) and Selzer et al. (2019). All three different terms have the same meaning; it is a concept of being perceptually present in the virtual environment generated by VR. However, Parmar et al. (2016) slightly distinguish it with the term "social presence" since they used virtual character for the research, but the concept is still the same as "presence". On the other hand, Leonard et al. (2020) investigated other VR features that showed distinct relationships namely social, embodied interactions and their expressed learning engagement in computational practices. They also stated that embodied experiences obtained in a VR environment allowed students to engage in a variety of computational practices.

Related to CT, it can be viewed from two designs as explained in section 3.1, CT as the learning outcome and CT as the strategy of learning. Turchi et al. (2019) designed $\mathrm{CT}$ as the learning outcome through collaborative game-based learning. The CT con- 
cepts considered in their research are decomposition, abstraction, algorithmic thinking, problem-solving, data representation, and debugging. Problem-solving is described as understanding what the goal of the problem is and finding a solution to solve it, while algorithmic thinking explained as a way to find a solution through a set of steps. In line with Turchi et al. (2019), Leonard et al. (2020) also designed CT as the learning outcome. CT concepts adopted in their research are sequence, loop, and variables. To measure the concept of sequence, students were asked to construct a dance movement of the virtual character and investigate how they accomplish it. Leonard et al. (2020) believed that the concept of a sequence is similar to dance choreography that has iteration. In the meanwhile, CT designed as the strategy of learning is applied by Lai et al. (2019) and Chen et al. (2020), namely problem decomposition, program algorithm, pattern recognition, and abstraction. Lai et al. (2019) integrated the concept of CT into a course on plot image-based VR. They stated that the used approaches are able to make students more familiar with scenarios, improve their learning interest and overall academic performance. Almost similar to Lai et al. (2019), Chen et al. (2020) employed the CT concept to allow students to think about the different script situations in a scenario of emergency disaster training. They stated that it is able to strengthen students' practical learning motivation and programming skills as well.

Based on the reviewed papers, the researchers stated that their design of studies has several impacts on learning. As the research conducted by Banic \& Gamboa (2019) said that self-directed learning of students in the concepts of computer programming was improved. Additionally, based on the observations, Banic \& Gamboa (2019) stated that students' creativity to find out solutions was increased as well and students independently sought to learn more computer programming concepts on their own. Even, Leonard et al. (2020) claimed that their interventions were able to change students' computational perspectives and mental model of who computer scientists. The majority revealed that their research may improve students' learning experiences, motivation, common sense, creative thinking, and systematic reasoning (Berns et al., 2019; Lai et al., 2019; Segura et al., 2020).

\subsection{Software and Hardware Devices}

Fig. 6 (a) illustrates the VR devices used in the 15 selected papers. Mostly, the papers did not clearly mention what the devices used in the researches, 57\% or more than half. They only mentioned head-mounted display (HMD) devices. Oculus, both Rift or Quest types, are the most used in the papers with a total of $33 \%$ or five articles. Meanwhile, only 14\% or two articles used HTC Vive to generated VR environments. The papers that utilized Oculus Rift in the researches are Parmar et al. (2016), Lin et al. (2017), Leonard et al. (2020), and Pearl et al. (2020), while Jin et al. (2020) used Oculus Quest type. The reason why Jin et al. (2020) chose this platform since it provides an all-in-one VR gaming system that may track users' motion without cables so that support immersive learning experiences. Andreas Dengel (2020) and Segura et al. (2020) used HTC Vive for their researches to construct the VR application system. 


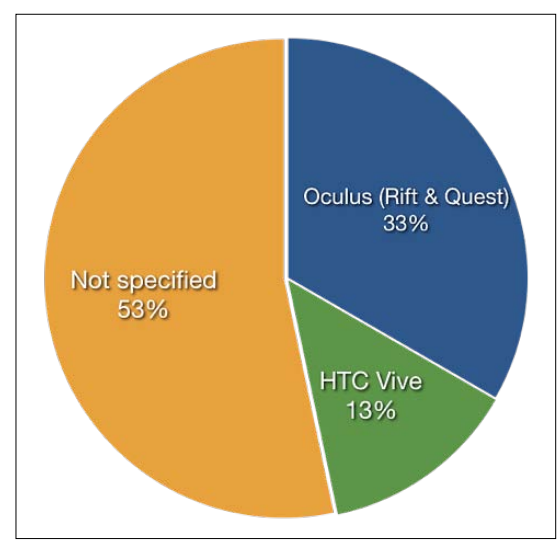

(a)

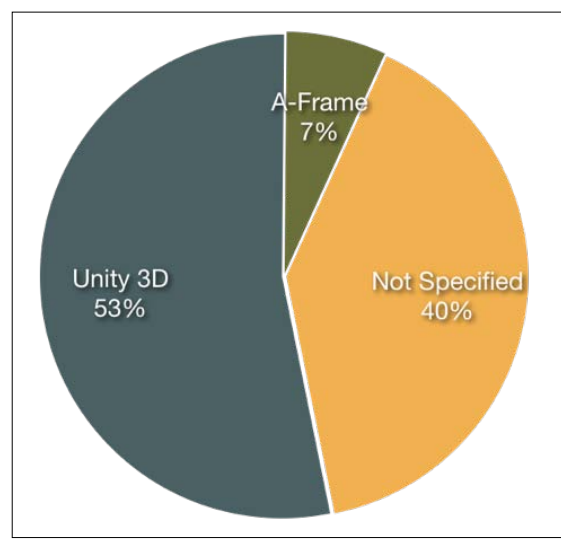

(b)

Fig. 6. (a) VR devices and (b) Software used to develop VR application.

Segura et al. (2020) selected HTC Vive because it is free and provides the functional plugin for other software like Unity 3D, so that may help developers to build user interfaces.

Unity 3D software is the type most used to build VR application systems as illustrated in Fig. 6(b), 53\% or 8 papers. This software is selected for several reasons as stated by Segura et al. (2020), (1) provides the required tools to create interactive 3D environments, (2) the documentation for application programming interface (API) is complete and well-documented, and (3) the software can be implemented for many different platforms like PCs, mobile devices, web-based, and even consoles. Meanwhile, 40\% or 6 papers did not mention what the type of software used in the researches is. One paper or 7\% used A-frame, web-based software to develop the VR application system, namely Berns et al. (2019). They chose A-frame due to the framework allows the developers to plug into an entity so that may add appearance, behavior, or functionality.

\section{Discussion}

Based on the articles reviewed above, we summarized several factors that can be considered to develop and implement the learning of CT skills through game based in VR settings. We proposed a conceptual framework to implement a strategy of learning CT skills through GBiVR as depicted in Fig. 7. Generally, it can be grouped into 3 parts, they are game elements, VR features, and CT concepts or CT skills. The Game elements and VR features can be encapsulated to be VRGACT (virtual reality game application for CT). The Game elements and VR features are positioned as the independent variables that intervene in CT skills as the dependent variables. We only selected several aspects of game elements, VR features, and CT concepts that should be considered in the proposed conceptual framework. This selection is based on the identification 


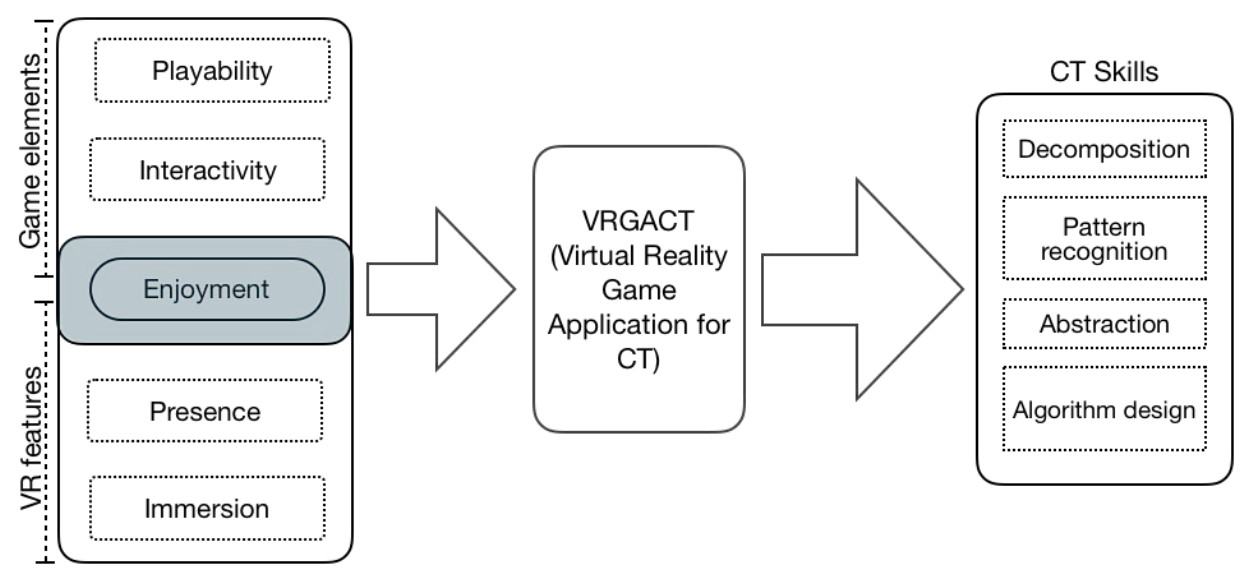

Fig. 7. Conceptual framework to implement the learning of CT skills through GBiVR.

and analysis conducted in the previous sections. The selected aspects in the proposed conceptual framework are playability and interactivity gained from game elements, while presence and immersion are the elements proposed from the VR environment. Meanwhile, enjoyment is variable generated by the combination of both game elements and VR features collectively. By playing game in the VRGACT world, users or students are expected to be more enjoy the designed environment and its gameplay. Finally, CT skills that we selected as the goal of learning are composed of decomposition, pattern recognition, abstraction, and algorithm design which in line with the research designed by Chen et al. (2020).

The first element is playability, which refers to the ability of VRGACT to provide an environment that allows users to play and learn at the same time as discussed in the section 3.3. It is in line with the research conducted by Turchi et al. (2019) that the VR-based game application should be playable and learnable to support learning to play and playing to learn. Playability is an important factor that should be considered while design a game since it is the core of the game and determine its quality (Paavilainen, 2020). Playability also describes the degree to which a game is fun to play and usable, with an emphasis on the interaction style and plot quality of the game (Usability First, 2020). The appropriate value of playability will give users obtaining more positive experience in assimilating the educational and playful concepts underlying the dynamic game.

Another important element in the conceptual framework is interactivity, which relates to the ability of VRGACT to respond and give appropriate feedback to users while playing. Hence, it can engage the users as the research carried out by Leonard et al. (2020). Interactivity establishes a two-way communication process between users or players as the learners and the features provided by the game apps. The communication will construct learning activities that involve the taught material contents and the available properties of the apps. In the GBiVR, interactivity can be designed in both physical and virtual forms, so that improve users' involvement and participation. The physical 
form can be designed as the embodied interaction, while the virtual form is the effect generated by the VRGACT system.

Elements of VR we proposed on the conceptual framework are presence and immersion. The presence or virtual presence is a concept of being perceptually present in a virtual environment so deeply as "if the medium were not there" (Selzer et al., 2019). The feature of presence makes the objects designed virtually become more real so that allows users to apply embodied interaction between users and the virtual objects as the research carried out by Leonard et al. (2020). By this feature, Leonard et al. (2020) found distinct relationships between students' social, embodied interactions, and learning engagement. Meanwhile, immersion in VR pertains to users' perception of being physically present in a non-physical world like a digital environment. This perception can be generated by visual displays, sounds, and other stimuli surrounding the users that influence the perception. Berns et al. (2019) stated in their researches that visual aspects or displays may improve overall learning experiences so that students enjoy to see the results produced by the VR game application system. The combination of game elements and VR features finally should make users enjoy to play and learn in the environment created by the application. When students enjoy the settings, they will automatically complete all the tasks provided by the system. Further, the factor of enjoyment will make users more engaged and self-directed learning as argued by Banic \& Gamboa (2019). That is why we selected enjoyment as the element that should be considered in the conceptual framework.

We propose CT skills as the dependent variables in the conceptual framework, which consists of four components, they are decomposition, pattern recognition, abstraction, and algorithm design. Actually, the definition of CT is varying due to the consensus of it has not been reached, but the majority of researchers do not dispute the definition (Selby \& Woollard, 2013). Chen et al. (2020) applied four CT components aforementioned to experiment with their research. Students were allowed to think about different script situations by CT concepts and discuss to find a suitable maker of the project to resolve disaster relief scenarios. In this research, students have a chance to demonstrate CT skills. The result shows that the practical motivation of the participants was strengthened. Decomposition refers to the ability to break a complex problem down into simpler parts so that it is easier to be handled. Among the simple problems as the result of decomposition are often found patterns. The ability to find out similarities or patterns among the decomposed problems in CT is called pattern recognition or sometimes called generalization. Abstraction pertains to the skill to remove or filtering out the characteristics of patterns that are not needed. Then, to execute and finish the recognized pattern problems are needed algorithm design or a set of step-by-step instructions to lead and tackle the problems.

Based on these reviews, the research conducted through this proposed conceptual framework can be evaluated by several approaches. For example, Chen et al. (2020) employed the technology acceptance model (TAM) to evaluate the students' experience of using VR game applications and the learning effectiveness after the experiments with CT concepts. On the other hand, Segura et al. (2020) used surveys to evaluate the user experience, general performance, and effectiveness of the developed application 
system. The surveys were developed by the team to find out the result directly from the participants. Hence, it can be stated that the evaluation strategy can be carried out by many approaches based on the need of the aspects that will be known.

\section{Conclusion}

According to the results and discussions obtained from the 15 reviewed papers, we proposed a conceptual framework to design an approach for learning CT through GBiVR settings. We categorized it into three main parts, they are game elements, VR features, and CT skills. The CT skills can be design in two ways, as learning outcomes and as the strategy of learning. In this conceptual framework, we more emphasize that CT is designed as the learning outcome. The study can be designed in experimental research or exploratory with two groups, intervention, and control group, to find out the differences. To make more engagement, the development of VRGACT application system should consider the elements of game and VR by optimizing the software and hardware function. Hence, students can be more engaged and enjoy the learning environment. This study contributes to the future design of the GBiVR framework to conduct a research related to the topics of CT, GBL, VR technology and its application. However, the articles that can be reviewed in this study are limited since the research on learning CT through GBiVR is still rarely conducted or perhaps currently in progress. This conceptual framework is constructed based on the previous studies. Therefore, experiments to students as the real participants are necessary to confirm the proposed framework and find out the impacts and limitations.

\section{Acknowledgments}

Thanks to Rector of Universitas Muhammadiyah Surakarta (UMS) and the Dean of Faculty of Teacher Training and Education UMS for supporting this study. The study is fully funded by Universitas Muhammadiyah Surakarta. This study is a part Doctor of Philosophy program in Information Technology Education, Faculty of Art, Computing, and Creative Industry, Universiti Pendidikan Sultan Idris, Malaysia.

\section{References}

Banic, A., Gamboa, R. (2019). Visual Design Problem-based Learning in a Virtual Environment Improves Computational Thinking and Programming Knowledge. 2019 IEEE Conference on Virtual Reality and 3D User Interfaces (VR), 1588-1593. https ://doi .org/10.1109/VR . 2019.8798013

Bavera, F., Quintero, T., Daniele, M., Buffarini, F. (2020). Computational Thinking Skills in Primary Teachers: Evaluation Using Bebras BT-Computer Science - CACIC 2019 (P. Pesado \& M. Arroyo (eds.); pp. 405-415). Springer International Publishing.

Berns, C., Chin, G., Savitz, J., Kiesling, J., Martin, F. (2019). MYR: A Web-Based Platform for Teaching Coding Using VR. Proceedings of the 50th ACM Technical Symposium on Computer Science Education, 77-83. https://doi.org/10.1145/3287324.3287482 
Cetin, I. (2016). Preservice Teachers'Introduction to Computing: Exploring Utilization of Scratch. JournalofEducational Computing Research, 54(7), 997-1021. https ://doi .org/10.1177/0735633116642774

Chen, S.-Y., Lai, Y.-H., Lin, Y.-S. (2020). Research on Head-Mounted Virtual Reality and Computational Thinking Experiments to Improve the Learning Effect of AIoT Maker Course: Case of Earthquake Relief Scenes. Frontiers in Psychology, 11, 1164. https://doi .org/10.3389/fpsyg. 2020.01164

Chou, P.-N. (2019). Using ScratchJr to Foster Young Children's Computational Thinking Competence: A Case Study in a Third-Grade Computer Class. Journal of Educational Computing Research, 0735633119872908. https://doi.org/10.1177/0735633119872908

Cleto, B., Sylla, C., Ferreira, L., Moura, J.M. (2020). CodeCubes: Coding with Augmented Reality. In R. Queirós, F. Portela, M. Pinto, \& A. Simões (Eds.), First International Computer Programming Education Conference (ICPEC 2020) (Vol. 81, pp. 7:1-7:9). Schloss Dagstuhl - Leibniz-Zentrum für Informatik. https://doi.org/10.4230/OASIcs. ICPEC.2020.7

Connolly, T.M., Boyle, E.A., MacArthur, E., Hainey, T., Boyle, J.M. (2012). A systematic literature review of empirical evidence on computer games and serious games. Computers \& Education, 59(2), 661-686. https://doi.org/https://doi.org/10.1016/j.compedu.2012.03.004

Cuny, J., Snyder, L., Wing, J.M. (2010). Demystifying computational thinking for non-computer scientists. Unpublished Manuscript in Progress, Referenced in http://Www.Cs.Cmu.Edu/CompThink/Resources/TheLinkWing.Pdf

Dengel, A. (2018). Seeking the Treasures of Theoretical Computer Science Education: Towards Educational Virtual Reality for the Visualization of Finite State Machines. 2018 IEEE International Conference on Teaching, Assessment, and Learning for Engineering (TALE), 1107-1112. https://doi.org/10.1109/TALE. 2018.8615288

Dengel, A. (2020). How Important is Immersion for Learning in Computer Science Replugged Games? Proceedings of the 51st ACM Technical Symposium on Computer Science Education, 1165-1171. https://doi.org/10.1145/3328778.3366837

Fagerlund, J., Häkkinen, P., Vesisenaho, M., Viiri, J. (2020). Assessing 4th Grade Students' Computational Thinking through Scratch Programming Projects. Informatics in Education, 19(4), 611-640. https://doi.org/10.15388/infedu.2020.27

Feng, Z., González, V.A., Amor, R., Lovreglio, R., Cabrera-Guerrero, G. (2018). Immersive virtual reality serious games for evacuation training and research: A systematic literature review. Computers \& Education, 127, 252-266. https://doi.org/https://doi.org/10.1016/j.compedu.2018.09.002

Hooshyar, D., Malva, L., Yang, Y., Pedaste, M., Wang, M., Lim, H. (2021). An adaptive educational computer game: Effects on students' knowledge and learning attitude in computational thinking. Computers in Human Behavior, 114, 106575. https ://doi .org/https://doi.org/10.1016/j.chb.2020.106575

Hsu, T.-C., Chang, S.-C., Hung, Y.-T. (2018). How to learn and how to teach computational thinking: Suggestions based on a review of the literature. Computers \& Education, 126, 296-310. https://doi.org/https://doi.org/10.1016/j.compedu.2018.07.004

Huang, W., Looi, C.-K. (2020). A critical review of literature on "unplugged" pedagogies in K-12 computer science and computational thinking education. Computer Science Education, 1-29. https://doi.org/10.1080/08993408.2020.1789411

Ilic, U., Haseski, H.İ., Tugtekin, U. (2018). Publication trends over 10 years of computational thinking research. Contemporary Educational Technology, 9(2), 131-153. https://doi.org/10.30935/cet. 414798

Jin, Q., Liu, Y., Yuan, Y., Yarosh, L., Rosenberg, E.S. (2020). VWorld: An Immersive VR System for Learning Programming. Proceedings of the 2020 ACM Interaction Design and Children Conference: Extended Abstracts, 235-240. https://doi.org/10.1145/3397617.3397843

Kao, D. (2019). JavaStrike: A Java Programming Engine Embedded in Virtual Worlds. Proceedings of the 14th International Conference on the Foundations of Digital Games. https://doi.org/10.1145/3337722.3341828

Kemdikbud, D. (2019). Kesiapan Sekolah Menengah Pertama dan Sekolah Menengah Atas dalam Menerapkan Informatika sebagai Mata Pelajaran pada Tahun 2019/2020.

Lai, Y.-H., Chen, S.-Y., Lai, C.-F., Chang, Y.-C., Su, Y.-S. (2019). Study on enhancing AIoT computational thinking skills by plot image-based VR. Interactive Learning Environments, 1-14. https://doi.org/10.1080/10494820.2019.1580750

Leonard, A.E., Daily, S.B., Jörg, S., Babu, S.V. (2020). Coding moves: Design and research of teaching computational thinking through dance choreography and virtual interactions. Journal of Research on Technology in Education, 1-19. https : //doi.org/10.1080/15391523.2020.1760754 
Liberati, A., Altman, D.G., Tetzlaff, J., Mulrow, C., Gøtzsche, P.C., Ioannidis, J.P.A., Clarke, M., Devereaux, P. J., Kleijnen, J., Moher, D. (2009). The PRISMA statement for reporting systematic reviews and metaanalyses of studies that evaluate healthcare interventions: explanation and elaboration. $B M J, 339, \mathrm{~b} 2700$. https://doi.org/10.1136/bmj.b2700

Lin, L., Parmar, D., Babu, S.V, Leonard, A.E., Daily, S.B., Jörg, S. (2017). How Character Customization Affects Learning in Computational Thinking. Proceedings of the ACM Symposium on Applied Perception. https://doi.org/10.1145/3119881.3119884

Lombard, M., Ditton, T. (1997). At the Heart of It All: The Concept of Presence. Journal of Computer-Mediated Communication, 3(2). https://doi .org/10.1111/j.1083-6101.1997.tb00072.x

Malva, L., Hooshyar, D., Yang, Y., Pedaste, M. (2020). Engaging Estonian primary school children in computational thinking through adaptive educational games: A qualitative study. 2020 IEEE 20th International Conference on Advanced Learning Technologies (ICALT), 188-190. https://doi.org/10.1109/ICALT49669.2020.00061

Nguyen, V.T., Zhang, Y., Jung, K., Xing, W., Dang, T. (2020). VRASP: A Virtual Reality Environment for Learning Answer Set Programming BT - Practical Aspects of Declarative Languages (E. Komendantskaya \& Y. A. Liu (eds.); pp. 82-91). Springer International Publishing.

Nietfeld, J. L. (2020). Predicting transfer from a game-based learning environment. Computers \& Education, 146, 103780. https://doi.org/https://doi.org/10.1016/j.compedu.2019.103780

Nouri, J., Zhang, L., Mannila, L., Norén, E. (2020). Development of computational thinking, digital competence and 21st century skills when learning programming in K-9. Education Inquiry, 11(1), 1-17. https://doi.org/10.1080/20004508.2019.1627844

Paavilainen, J. (2020). Defining Playability of Games: Functionality, Usability, and Gameplay. Proceedings of the 23rd International Conference on Academic Mindtrek, 55-64.

https://doi.org/10.1145/3377290.3377309

Parmar, D., Isaac, J., Babu, S.V, D’Souza, N., Leonard, A.E., Jörg, S., Gundersen, K., Daily, S. B. (2016). Programming moves: Design and evaluation of applying embodied interaction in virtual environments to enhance computational thinking in middle school students. 2016 IEEE Virtual Reality (VR), 131-140. https://doi.org/10.1109/VR.2016.7504696

Pearl, H., Arrants, S., Swanson, H., Trninic, D. (2020). The AL Goldberg Machine: A Virtual Environment for Engaging Learners in Algorithmic Practices. Proceedings of the 2020 ACM Interaction Design and Children Conference: Extended Abstracts, 211-216. https://doi .org/10.1145/3397617. 3397845

Radianti, J., Majchrzak, T.A., Fromm, J., Wohlgenannt, I. (2020). A systematic review of immersive virtual reality applications for higher education: Design elements, lessons learned, and research agenda. Computers \& Education, 147, 103778.

https://doi.org/https://doi.org/10.1016/j. compedu. 2019.103778

Román-González, M., Pérez-González, J.-C., Jiménez-Fernández, C. (2017). Which cognitive abilities underlie computational thinking? Criterion validity of the Computational Thinking Test. Computers in Human Behavior, 72, 678-691. https://doi.org/https://doi.org/10.1016/j.chb.2016.08.047

Saad, A. (2020). Students' Computational Thinking Skill through Cooperative Learning Based on Hands-on, Inquiry-based, and Student-centric Learning Approaches. Universal Journal of Educational Research, 8(1), 290-296.

Salvador-Ullauri, L., Acosta-Vargas, P., Luján-Mora, S. (2020). Web-Based Serious Games and Accessibility: A Systematic Literature Review. In Applied Sciences (Vol. 10, Issue 21). https://doi.org/10.3390/app10217859

Segura, R.J., del Pino, F.J., Ogáyar, C.J., Rueda, A.J. (2020). VR-OCKS: A virtual reality game for learning the basic concepts of programming. Computer Applications in Engineering Education, 28(1), 31-41. https://doi.org/https://doi.org/10.1002/cae. 22172

Selby, C., Woollard, J. (2013). Computational thinking: the developing definition. University of Southampton (E-prints). https://eprints . soton.ac.uk/356481/

Selzer, M.N., Gazcon, N.F., Larrea, M.L. (2019). Effects of virtual presence and learning outcome using lowend virtual reality systems. Displays, 59, 9-15.

https://doi.org/https://doi.org/10.1016/j.displa.2019.04.002

Shi, A., Wang, Y., Ding, N. (2019). The effect of game-based immersive virtual reality learning environment on learning outcomes: designing an intrinsic integrated educational game for pre-class learning. Interactive Learning Environments, 1-14. https://doi .org/10.1080/10494820.2019.1681467

Tang, K.-Y., Chou, T.-L., Tsai, C.-C. (2020). A Content Analysis of Computational Thinking Research: An 
International Publication Trends and Research Typology. The Asia-Pacific Education Researcher, 29(1), 9-19. https://doi.org/10.1007/s40299-019-00442-8

Turchi, T., Fogli, D., Malizia, A. (2019). Fostering computational thinking through collaborative game-based learning. Multimedia Tools and Applications, 78(10), 13649-13673.

https://doi.org/10.1007/s11042-019-7229-9

Usability First. (2020). Playability (Glossary). Foraker Labs. https://www.usabilityfirst.com/glossary/playability/

Wing, J.M. (2006). Computational Thinking. Commun. ACM, 49(3), 33-35. https://doi.org/10.1145/1118178.1118215

Wohlin, C. (2014). Guidelines for Snowballing in Systematic Literature Studies and a Replication in Software Engineering. Proceedings of the 18th International Conference on Evaluation and Assessment in Software Engineering. https://doi .org/10.1145/2601248.2601268

Yang, K., Liu, X., Chen, G. (2020). The Influence of Robots on Students? Computational Thinking: A Literature Review. International Journal of Information and Education Technology, 10(8).

$\mathrm{Yu}$, J., Roque, R. (2019). A review of computational toys and kits for young children. International Journal of Child-Computer Interaction, 21, 17-36. https://doi.org/https://doi.org/10.1016/j.ijcci.2019.04.001

Zhang, L., Nouri, J. (2019). A systematic review of learning computational thinking through Scratch in K-9. Computers \& Education, 141, 103607.

https://doi.org/https://doi.org/10.1016/j.compedu.2019.103607

Zhao, W., Shute, V.J. (2019). Can playing a video game foster computational thinking skills? Computers \& Education, 141, 103633. https://doi.org/https://doi.org/10.1016/j.compedu.2019.103633

S. Sukirman is a staff of Informatics Engineering Department, Faculty of Teacher Training and Education, Universitas Muhammadiyah Surakarta (UMS), Indonesia. He takes Doctor of Philosophy program in Information Technology Education, Faculty of Art, Computing, and Creative Industry, Universiti Pendidikan Sultan Idris (UPSI), Malaysia. His research interests are computational thinking, game-based learning, virtual and augmented (mixed) reality for educational purposes.

L.F.M. Ibharim is a senior lecturer at the Computing Department, Faculty of Art, Computing and Creative Industry, Universiti Pendidikan Sultan Idris (UPSI). She has graduated with her Ph.D. in Multimedia in Education. She has been teaching game design and development courses from 2011 until the present. Various agencies are often invited her as a consultant and trainee for teaching and learning courses, especially for gamification and game-based learning. Her interests are any research projects or practices in Game Design and Development, Game-Based Learning, Gamification, Human-Computer Interaction, Usability Engineering, and Multimedia in Education, specifically designing technologies and content creation. 
C.S. Said is a senior lecturer of the Deparment of Computing, Faculty of Art, Computing and Creative Industry, Universiti Pendidikan Sultan Idris. He holds master of science in computer science from Universiti Putra Malaysia, and Ph.D degree in instructional technology from Universiti Sains Malaysia. His research interest including study the impact of virtual environment, gaming and multimedia technologies in education.

B. Murtiyasa is a Professor of Mathematics Education, Universitas Muhammadiyah Surakarta, Indonesia. Research interests in the field of ICT in education include the use of technology to improve the quality of learning and its management. Some of the research topics that have been carried out include the development of smart classes, ICT-based multimedia development, and mobile learning. Currently doing research on gamification in mathematics learning. He is also active in providing training for young lecturers in the field of learning technology. 